\title{
Two-fold tandem acyl-group shift/cyclization via gold catalysis
}

\author{
Antoine Simonneau, ${ }^{a}$ Giovanni Maestri, ${ }^{b}$ Louis Fensterbank, ${ }^{*^{a}}$ and Max Malacria*a,b \\ ${ }^{a}$ Institut Parisien de Chimie Moleculaire, UPMC Université Paris 06, IPCM-UMR 7201, \\ 4 Pl. Jussieu, C. 229, Paris Cedex 75005, France \\ ${ }^{b}$ Institut de Chimie des Substances Naturelles, ICNS-CNRS UPR2301, 1, avenue de la Terrasse \\ Bât.27, Gif/Yvette Cedex 91198, France \\ E-mail: max.malacria@upmc.fr, louis.fensterbank@upcm.fr
}

Dedicated to Professor Pierre Vogel on the occasion of his $70^{\text {th }}$ birthday

\begin{abstract}
A complex cascade involving allendiynes in the presence of a cationic gold catalyst is described. The process features two sequential acyl-group shift/cyclization steps eventually delivering a bicyclic furan derivative from the acyclic precursor. A controlled sequence of molecular events can thus readily deliver the desired heterocycle with a remarkable selectivity.
\end{abstract}

Keywords: Allene, cycloisomerization, gold, heterocycles, catalysis

\section{Introduction}

The synthesis of functionalized cyclic frameworks in a concise fashion has always been of particular interest for synthetic chemists in their continuing effort to disclose new reactivities and more efficient methodologies. ${ }^{1,35}$ The access to polycyclic scaffolds of high molecular complexity $^{2}$ in a concise manner through elaborate cascade reactions is a particularly challenging goal that continues to inspire the creativity of scientists. ${ }^{3-6}$ Selective carbocyclization by activation of unsaturated $\mathrm{C}-\mathrm{C}$ multiple bonds in acyclic precursors under transition metal catalyses plays a relevant role in this context mainly thanks to its unique possibility to overcome limitations connected to other conventional methods. ${ }^{4-17}$ In this field, gold-catalyzed cycloisomerization reactions of poly-unsaturated substrates received the attention of many research groups in the last few years. ${ }^{18-20}$ Recently, a straightforward access to polyconjugated bis-enones has been reported by our group via a gold-catalyzed tandem 1,3-acyloxy migration/cyclization/1,5-acyl-shift of linear diynes (Scheme 1). ${ }^{21}$ 


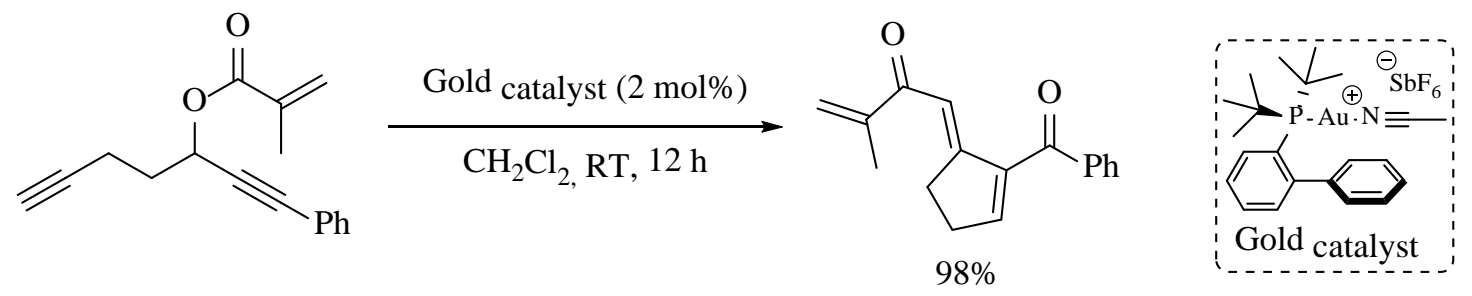

Scheme 1. Access to conjugated bis-enones via gold catalysis

We asked ourselves whether it would be possible to increase the already remarkable complexity of the sequence by testing this methodology on substrates bearing an allene functionality in place of the unreacted alkene in the above depicted reaction (Scheme 1).

\section{Results and Discussion}

Our study focused on a suitable diyne substrate 5 bearing an allenyl ester (Scheme 2). Synthesis of this acyclic precursor was realized from pent-4-yn-1-ol (1), which was monosilylated at the acetylenic position by double deprotonation with $n$-butyllithium, addition of two equivalents of trimethylsilyl chloride and subsequent treatment with aqueous $\mathrm{HCl}$. Oxidation of the resulting alcohol with pyridinium chlorochromate delivered aldehyde 2 . This aldehyde was then treated with deprotonated phenylacetylene to furnish a propargylic alcohol that was next esterified using bromoacetyl bromide to give diyne 3 . Reaction with triphenylphosphine followed by base treatment furnished the phosphorus ylide 4, which was employed in the next step without purification. Installation of the allene moiety was performed by reaction of ylide $\mathbf{3}$ with ketene, generated in situ from acyl chloride and triethylamine. ${ }^{22-27}$ Allenoyl derivative $\mathbf{4}$ could thus be obtained in $80 \%$ yield from $\alpha$-bromoester 3 . Final desilylation by means of potassium fluoride delivered 5 possessing the desired terminal triple bond in 63\% yield.

We then examined the reactivity of 5 in the presence of catalytic amounts (4 mol\%) of Echavarren's cationic gold(I) catalyst ${ }^{28}$ in dichloromethane at room temperature, conditions that proved to be optimal in our previous study. We were delighted to observe the sole formation of furan derivative 6, which also readily occurred with only $2 \mathrm{~mol} \%$ of the catalyst without hampering substrate conversion. Product 6 could thus be obtained in a good 74\% isolated yield. Further reduction of catalyst loading leads however to sluggish reactions. The selective incorporation of the allene fragment in the heterocyclic skeleton of 7 (see below for the mechanistic discussion) proves the feasibility of further expanding the molecular complexity achievable within these cascades in a controlled manner. 

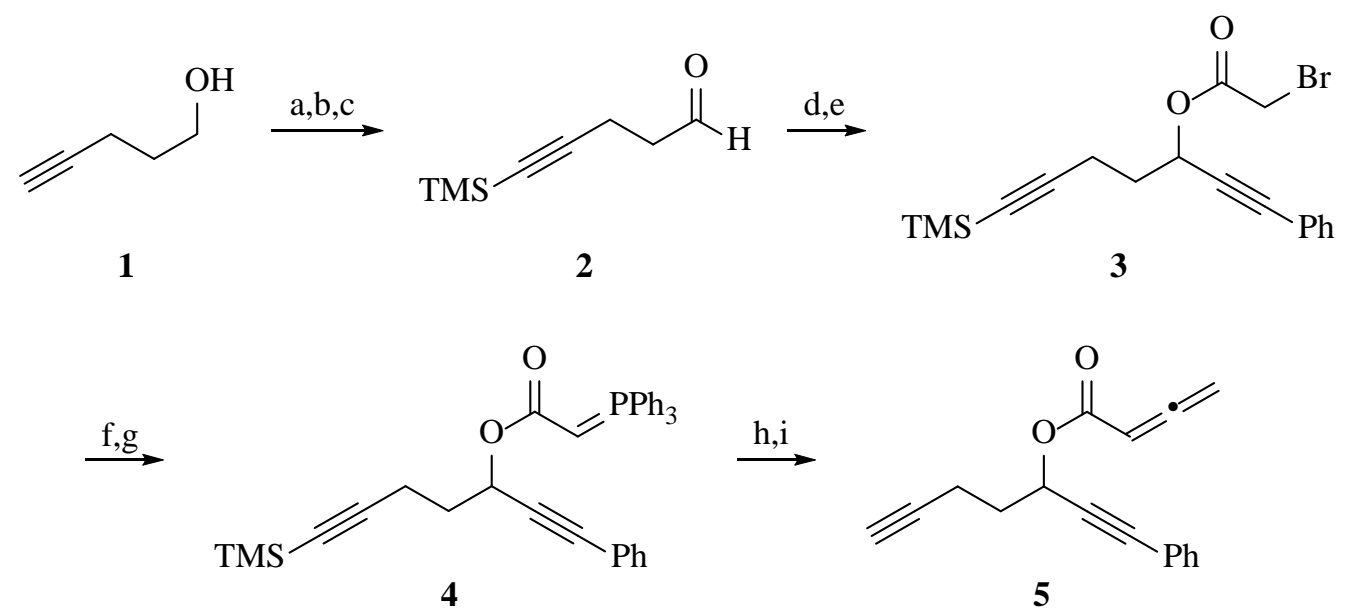

Conditions: (a) n-BuLi, TMSCl, THF, $-78^{\circ} \mathrm{C}$ to rt; (b) $2 \mathrm{~N} \mathrm{HCl}$; (c) PCC, DCM, 68\% over 3 steps; (d) PhCCLi, THF, $-78{ }^{\circ} \mathrm{C}$ to rt, 88\%; (e) Bromoacetyl bromide, DCM, rt, 4 d; (f) $\mathrm{PPh}_{3}$, MeCN, rt, 53\% over 2 steps; (g) NaOH 1.2M, DCM; (h) AcCl, NEt 3 , DCM, rt, 80\% over 2 steps; (i) KF, DMSO, 63\%.

Scheme 2. Synthesis of allenoyl substrate 5 .

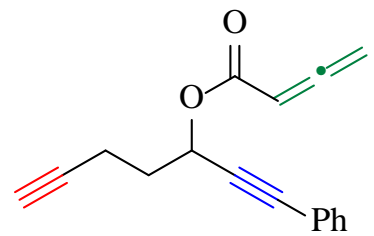

5

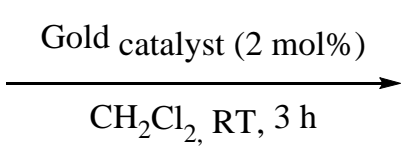

$$
\mathrm{CH}_{2} \mathrm{Cl}_{2}, \mathrm{RT}, 3 \mathrm{~h}
$$

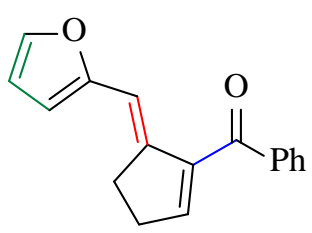

6, $74 \%$

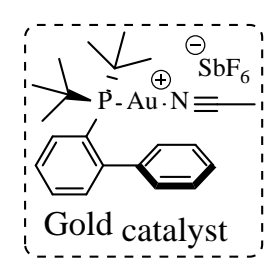

Gold catalyst

Optimized reaction conditions: at room temperature under argon for 3 hours, substrate conversion monitored by TLC, $0.5 \mathrm{M}$ on substrate at the $0.2 \mathrm{mmol}$ scale.

Scheme 3. Catalytic synthesis of polyconjugated furan $\mathbf{6}$ from acyclic allene derivative $\mathbf{5}$

Scheme 4 presents the ${ }^{1} \mathrm{H}$ and ${ }^{13} \mathrm{C}$ NMR spectra of allene 5 (top) and furan 6 (down) respectively. The gold-catalyzed cyclization leading to $\mathbf{6}$ is witnessed by the disappearance of the allene and alkynes resonances and the corresponding appearance of vinylic and furyl ones. 

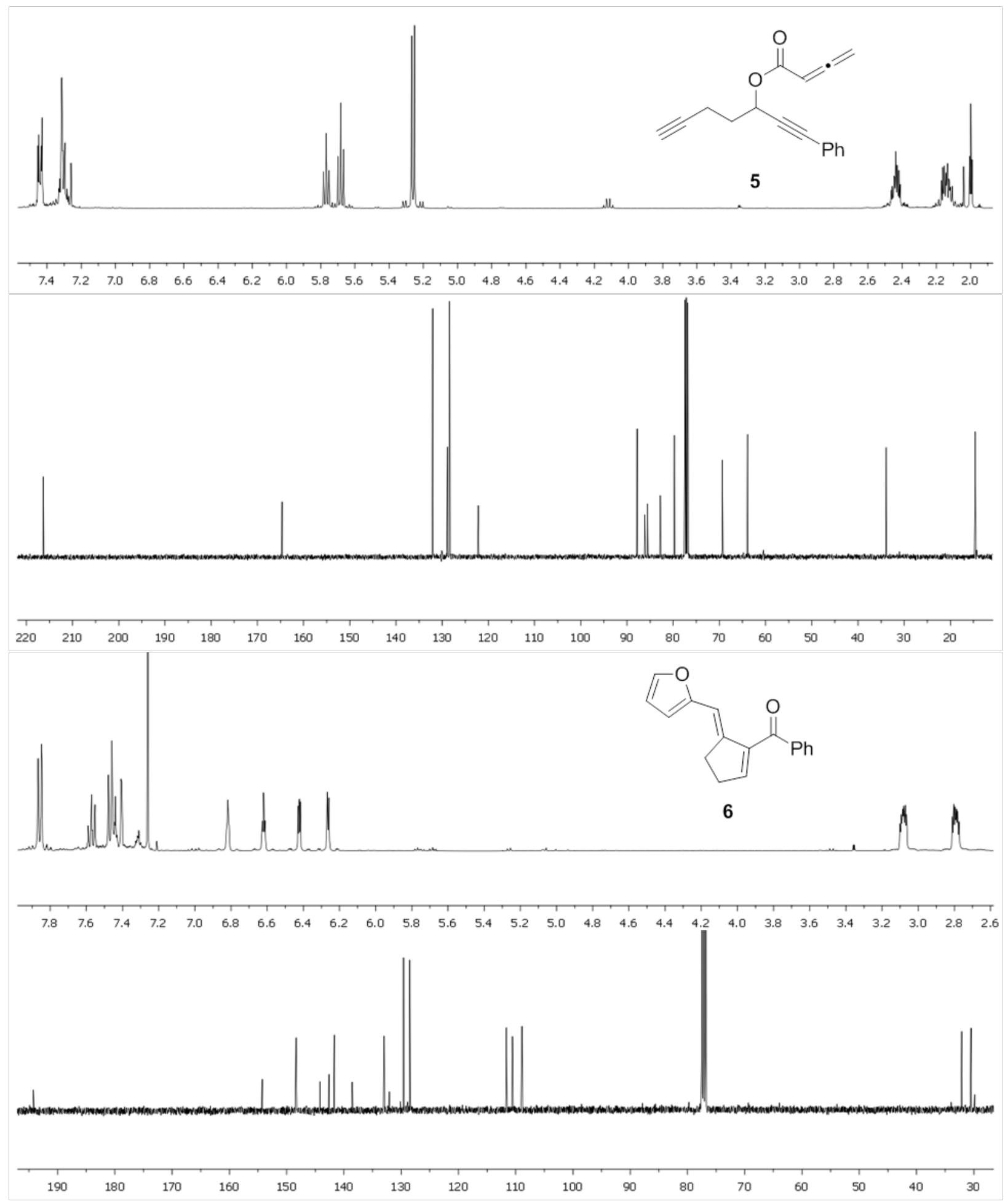

Scheme 4. Comparison of ${ }^{1} \mathrm{H}$ and ${ }^{13} \mathrm{C}$ NMR spectra of allene 5 (top) and furan 6 (down).

Providing a mechanistic rationale for this reaction was straightforward in view of previous studies by us and others (Scheme 5). 


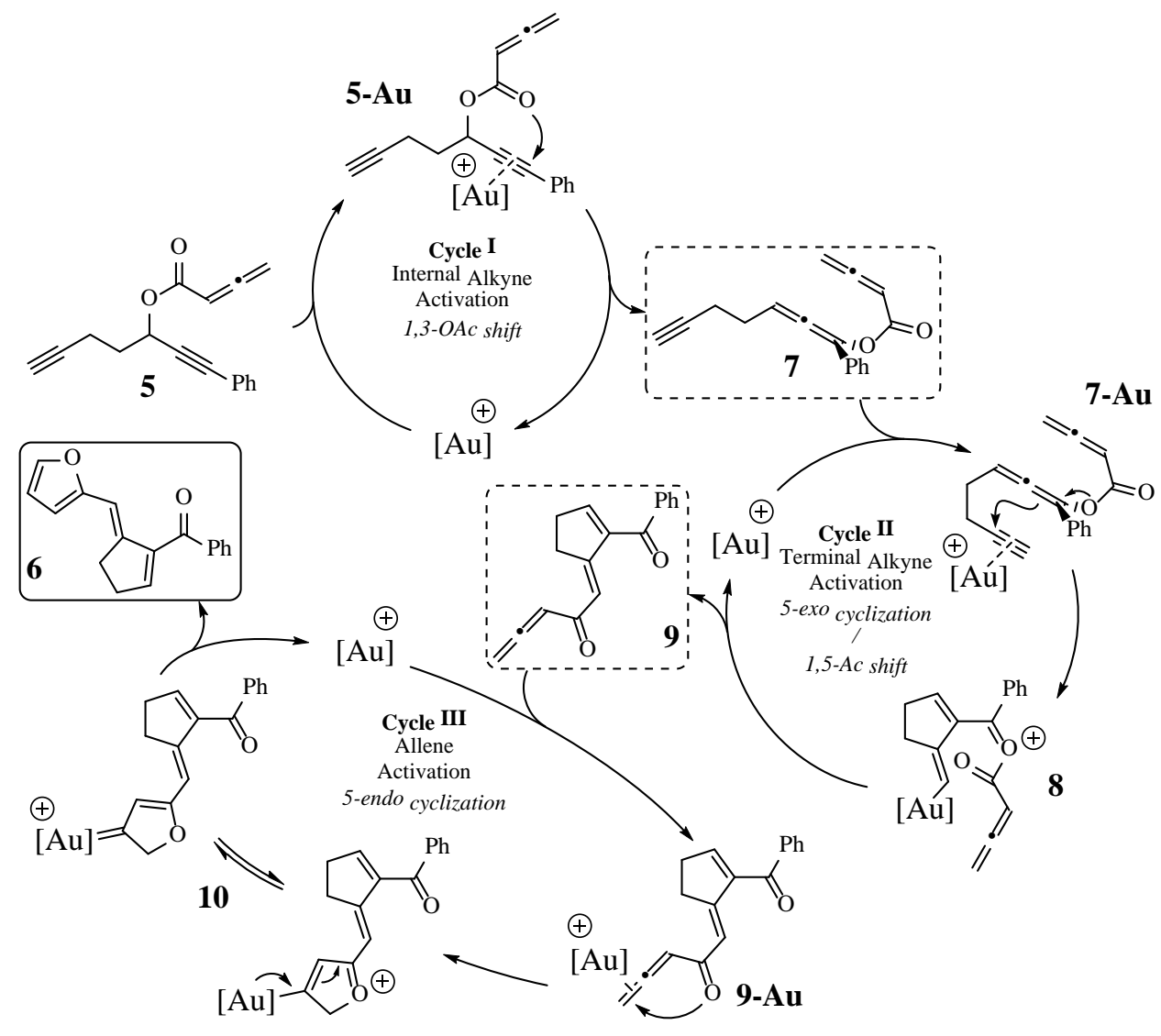

Scheme 5. Proposed reaction mechanism

Computational and experimental work from our team has established a sequence leading from 5 to 9 as a viable route to the bis-enone $\mathbf{9}^{21}$ This sequence involves an initial 1,3-acyloxy shift to provide the corresponding allenyl ester 7 (Cycle I in Scheme 4). ${ }^{29-31}$ The cationic gold catalyst then coordinates to the least hindered unsaturation, namely the terminal alkyne fragment, triggering the cyclization of the most electron-rich allene in 7-Au. The favored 5-exo-dig process delivers vinylgold intermediate 8 that can subsequently evolve to $\mathbf{9}$ via a 1,5-acyl transfer (Cycle II in Scheme 4). According to previous double-tagging experiments ${ }^{21}$ employing deuterated substrates, this step presumably occurs through an intramolecular mechanism. The stereoselectivity of the acyl transfer has been modeled via DFT on simplified substrates and revealed the energetic convenience of formation of $\mathbf{9}$ in a concerted, asynchronous fashion in respect to its opposite isomer owing to reduced steric congestion. Likely, replacing the acyl group used for modeling with a more sterically demanding allene will increase the formation of 9 possessing the $(E)$-exocyclic double bond. Activation of the terminal allenic position by gold in 9-Au allows its activation and the furan ring of $\mathbf{6}$ eventually forms via 5-endo-dig cyclization presumably through equilibrium 10 (Cycle III in Scheme 4). ${ }^{32-33}$ A similar reactivity of allenones has been recently reported by Alcaide and Almendros for the synthesis of 2-substituted furans via $\mathrm{Au}(\mathrm{I})$ catalysis. $^{34}$ Propargylic allenols The overall selectivity of this cascade is indeed 
outstanding reasoning on the sequential order of molecular events that readily takes place. Within the same molecule, three different $\mathrm{C}-\mathrm{C}$ multiple bonds are activated by the gold catalyst through three distinct catalytic cycles, in a sequential order (alkyne-alkyne-allene) to afford ultimately the heterocyclic product.

\section{Conclusions}

A concise conjugated furan synthesis of has been developed by means of cationic gold catalysis. The complex sequence generates the bicyclic product via a two-fold sequential acyl group migrations/cyclizations steps. Careful tuning of the stereoelectronic properties of the substrates makes then possible to achieve high molecular complexity in one pot and with remarkable selectivity.

\section{Experimental Section}

Unless specially mentioned all reactions were carried out under an anhydrous argon atmosphere in flame-dried glassware. Reagents were purchased from commercial sources and used as received. Solvents were systematically distilled using standard procedures and degassed prior to use.

1-Phenyl-7-(trimethylsilyl)hepta-1,6-diyn-3-ol. To a solution of 4-pentynol 1 (5.9 g, $70 \mathrm{mmol}$, 1.0 equiv.) in THF (100 mL) was added dropwise at $-78{ }^{\circ} \mathrm{C} n$-butyllithium $(2.50 \mathrm{M}$ in hexanes, $60.0 \mathrm{~mL}, 147 \mathrm{mmol}, 2.10$ equiv.). The mixture was slowly allowed to warm to rt, then cooled again to $-78{ }^{\circ} \mathrm{C}$. Freshly distilled TMSCl $(20.0 \mathrm{~mL}, 154 \mathrm{mmol}, 2.20$ equiv.) was then added dropwise to the mixture, which was then allowed to warm to rt. Stirring was kept for $2 \mathrm{~h}$. The mixture was then quenched with a $3 \mathrm{M} \mathrm{HCl}$ aqueous solution and the resulting biphasic system was vigorously stirred for 3 hours. The aqueous layer was extracted twice with $\mathrm{Et}_{2} \mathrm{O}$ and the combined organic extracts were washed with brine, dried over anhydrous $\mathrm{MgSO}_{4}$, filtered and evaporated to give 5-trimethylsilyl-4-pentynol 1 quantitatively. 5-Trimethylsilyl-4-pentynol $\mathbf{1}$ ( $4.00 \mathrm{~g}, 25.6 \mathrm{mmol}, 1.00$ equiv.) was added dropwise at rt to a suspension of PCC (8.30 g, 38.4 mmol, 1.50 equiv.) in $\mathrm{CH}_{2} \mathrm{Cl}_{2}(60 \mathrm{~mL})$. The reaction mixture was stirred at rt for $2 \mathrm{~h}$, then diluted with $\mathrm{Et}_{2} \mathrm{O}$ and filtered over celite. The solid was washed several times with $\mathrm{Et}_{2} \mathrm{O}$ and the filtrate was concentrated under reduced pressure. Purification by flash column chromatography over silica gel using a 8:2 pentane/ $\mathrm{Et}_{2} \mathrm{O}$ mixture afforded pure 5-trimethylsilyl-4-pentynal (2) in 68\% yield over the two steps. Alkynylation of the aldehyde was realized with phenyl acetylene upon deprotonation of the latter with $n$-butyllithium (in THF at $-78^{\circ} \mathrm{C}$, following the above-mentioned method) to eventually provide the desired diyne as a yellow oil in $\mathrm{MgSO}_{4} 88 \%$ yield after flash column chromatography. ${ }^{1} \mathrm{H}$ NMR $\left(400 \mathrm{MHz}, \mathrm{CDCl}_{3}\right) \delta 7.37-7.29$ (m, 5H), 4.76 (q, $J=6.2 \mathrm{~Hz}$, 
1H), $2.59-2.41$ (m, 2H), 2.13 (d, $J=5.7 \mathrm{~Hz}, 1 \mathrm{H}), 2.02$ (q, $J=7.0 \mathrm{~Hz}, 2 \mathrm{H}), 0.16$ (s, 9H). HRMS calcd. for $\mathrm{C}_{16} \mathrm{H}_{21} \mathrm{OSi}^{+}(\mathrm{M}+\mathrm{H})^{+}$257.1362, found 257.1356. Other spectroscopic data of this compound match those previously reported. ${ }^{21}$

1-Phenyl-7-(trimethylsilyl)hepta-1,6-diyn-3-yl 2-bromoacetate (3). To a solution of the alcohol (750 mg, $2.93 \mathrm{mmol}, 1.00$ equiv.) in DCM (30 mL) was added dropwise at $0{ }^{\circ} \mathrm{C}$ bromoacetyl bromide $(0.512 \mathrm{~mL}, 5.86 \mathrm{mmol}, 2.00$ equiv.). The mixture was stirred at rt for 4 days, then quenched with a $10 \%$ aqueous solution of potassium carbonate. The aqueous phase was extracted with DCM and the combined organic extracts were then washed with brine, dried over magnesium sulfate and filtered. After removal of solvents under reduced pressure, the crude mixture was purified by flash column chromatography to provide the bromoacetate derivative as pale brown oil in 55\% yield. ${ }^{1} \mathrm{H}$ NMR (300 MHz, $\left.\mathrm{CD}_{3} \mathrm{CN}\right) \delta 7.44$ (dd, $J=7.3,2.1 \mathrm{~Hz}, 2 \mathrm{H}$ ), 7.36 - 7.28 (m, 3H), 5.74 (t, $J=6.4 \mathrm{~Hz}, 1 \mathrm{H}), 3.88$ (s, 2H), 2.49 (t, $J=7.5 \mathrm{~Hz}, 2 \mathrm{H}), 2.15$ (q, $J=6.8$ $\mathrm{Hz}, 2 \mathrm{H}$ ), 0.87 (q, $J=6.7,5.8 \mathrm{~Hz}, 1 \mathrm{H}), 0.16$ (s, 9H). HRMS calcd. for $\mathrm{C}_{18} \mathrm{H}_{22} \mathrm{O}_{2} \mathrm{BrSi}^{+}(\mathrm{M}+\mathrm{H}$, $\left.{ }^{79} \mathrm{Br}\right)^{+}$377.0572, found 377.0569.

(2-oxo-2-((1-phenyl-7-(trimethylsilyl)hepta-1,6-diyn-3-yl)oxy)ethyl)triphenylphosphonium bromide. To a solution of bromoacetate 3 (465 mg, $1.20 \mathrm{mmol}, 1.00$ equiv.) in MeCN (90 mL) was added triphenylphosphine (388 mg, $1.50 \mathrm{mmol}, 1.20$ equiv.). The reaction was stirred at $\mathrm{rt}$ for 24 hours and the solvent was then removed under reduced pressure to give a brown foam. The latter was washed twice with diethyl ether to give the desired phosphonium salt as a pale brown solid in quantitative yield. ${ }^{1} \mathrm{H}$ NMR (400 MHz, $\left.\mathrm{CD}_{3} \mathrm{CN}\right) \delta 7.92-7.76(\mathrm{~m}, 10 \mathrm{H}), 7.71-$ $7.61(\mathrm{~m}, 7 \mathrm{H}), 7.43-7.30(\mathrm{~m}, 6 \mathrm{H}), 5.56(\mathrm{t}, J=6.4 \mathrm{~Hz}, 1 \mathrm{H}), 5.47-5.24(\mathrm{~m}, 2 \mathrm{H}), 2.37-2.15(\mathrm{~m}$, 2H), 1.84 (q, $J=7.4 \mathrm{~Hz}, 2 \mathrm{H}), 0.10$ (s, 9H). ${ }^{31} \mathrm{P}$ NMR (162 MHz, CD $\left.{ }_{3} \mathrm{CN}\right) \delta 21.8$ (t, $J=26.4 \mathrm{~Hz}$ ). ${ }^{13} \mathrm{C}$ NMR (101 MHz, CD $\left.{ }_{3} \mathrm{CN}\right) \delta 164.3,136.1$ (d, $\left.J=2.8 \mathrm{~Hz}, 3 \mathrm{C}\right), 134.9$ (d, $\left.J=10.8 \mathrm{~Hz}, 6 \mathrm{C}\right)$, 134.27 (d, $J=19.6 \mathrm{~Hz}, 3 \mathrm{C}$ ), 132.6 (2C), 130.9 (d, $J=13.2 \mathrm{~Hz}, 6 \mathrm{C}$ ), 130.1, 129.5 (2C), 122.1, 119.1, 106.1, 87.2, 86.2, 85.2, 66.4, 34.0, 32.5, 32.0, 16.1, 0.0 (3C). HRMS calcd. for $\mathrm{C}_{36} \mathrm{H}_{36} \mathrm{O}_{2} \mathrm{PSi}^{+}\left(\mathrm{M}-\mathrm{Br}^{-}\right)^{+}$559.2222, found 559.2228.

1-Phenyl-7-(trimethylsilyl)hepta-1,6-diyn-3-yl buta-2,3-dienoate (5). The phosphonium salt (495 mg, $0.770 \mathrm{mmol}, 1.00$ equiv.) was diluted in $2 \mathrm{~mL}$ of DCM and the solution was introduced in a small separatory funnel. $1.3 \mathrm{~mL}$ of a 1.2 M solution of $\mathrm{NaOH}$ (1.55 mmol, 2.00 equiv.) were added and the biphasic system was vigorously shaken. The aqueous layer was then extracted with DCM and the combined organic extracts were dried over magnesium sulfate, filtered and concentrated under reduced pressure. The resulting brown oil was diluted with DCM (8 mL). Triethylamine (1.1 equiv.) was then added to the solution followed by dropwise addition of 1.1 equiv. of acetyl chloride at rt. The resulting mixture was kept under stirring overnight, then filtered through a short pad of silica gel using a 2:1 mixture of pentane/diethylether as eluent. The desired TMS-protected allenoyl was eventually retrieved as a pale brown oil in $80 \%$ yield. ${ }^{1} \mathrm{H}$ NMR (400 MHz, $\left.\mathrm{CDCl}_{3}\right) \delta 7.46-7.42(\mathrm{~m}, 2 \mathrm{H}), 7.34-7.28(\mathrm{~m}, 3 \mathrm{H}), 5.73(\mathrm{t}, J=6.4 \mathrm{~Hz}, 1 \mathrm{H})$, $5.68(\mathrm{t}, J=6.5 \mathrm{~Hz}, 1 \mathrm{H}), 5.26$ (d, $J=6.6 \mathrm{~Hz}, 2 \mathrm{H}), 2.51-2.44(\mathrm{~m}, 2 \mathrm{H}), 2.17-2.09(\mathrm{~m}, 2 \mathrm{H}), 0.15$ (s, 9H). ${ }^{13} \mathrm{C}$ NMR (101 MHz, $\left.\mathrm{CDCl}_{3}\right) \delta$ 216.3, 164.6, 132.1 (2C), 128.8, 128.4 (2C), 122.2, 105.4, 87.8, 86.1, 85.7, 85.6, 79.7, 64.0, 34.1, 16.0, 0.2 (3C). HRMS calcd. for $\mathrm{C}_{20} \mathrm{H}_{23} \mathrm{O}_{2} \mathrm{Si}^{+}$ 
$(\mathrm{M}+\mathrm{H})^{+}$323.1467, found 323.1460.

1-Phenylhepta-1,6-diyn-3-yl buta-2,3-dienoate (5). To a solution of the silylated alkyne in DMSO (0.5 M) were added few drops of water and potassium fluoride (4 equiv.). The reaction was stirred at rt for $24 \mathrm{~h}$ and then diluted in diethyl ether. The resulting mixture was washed twice with water and dried over $\mathrm{MgSO}_{4}$. The solvent was evaporated under reduced pressure and the crude product purified by flash column chromatography over silica gel using gradient mixtures of pentane and diethyl ether. The desired allenoyl derivative was obtained as a pale brown oil in $63 \%$ yield. ${ }^{1} \mathrm{H}$ NMR $\left(400 \mathrm{MHz}, \mathrm{CDCl}_{3}\right) \delta 7.46-7.42(\mathrm{~m}, 2 \mathrm{H}), 7.34-7.28(\mathrm{~m}, 3 \mathrm{H})$, $5.77(\mathrm{t}, J=6.4 \mathrm{~Hz}, 1 \mathrm{H}), 5.68(\mathrm{t}, J=6.5 \mathrm{~Hz}, 1 \mathrm{H}), 5.26$ (d, $J=6.6 \mathrm{~Hz}, 2 \mathrm{H}), 2.47-2.41(\mathrm{~m}, 2 \mathrm{H})$, $2.18-2.10(\mathrm{~m}, 2 \mathrm{H}), 2.00(\mathrm{t}, J=2.7 \mathrm{~Hz}, 1 \mathrm{H}) .{ }^{13} \mathrm{C}$ NMR $\left(101 \mathrm{MHz}, \mathrm{CDCl}_{3}\right) \delta 216.4,164.7,132.1$ (2C), 128.9, 128.4 (2C), 122.2, 87.8, 86.1, 85.6, 82.8, 79.7, 69.4, 63.9, 33.9, 14.7. IR (neat) $v=$ 3296, 2232, 1969, 1715, 1244, 1149, 854, 757, 690, $636 \mathrm{~cm}^{-1}$. HRMS calcd. for $\mathrm{C}_{17} \mathrm{H}_{15} \mathrm{O}_{2}^{+}$ $(\mathrm{M}+\mathrm{H})^{+}$251.1067, found 251.1072.

(E)-(5-(Furan-2-ylmethylene)cyclopent-1-en-1-yl)(phenyl)methanone (6). The allenoyl derivative 5 (50 mg, $0.2 \mathrm{mmol}$ ) was weighted into an oven-dried Schlenk flask. At least three vacuum/argon cycles were then made before adding via syringe freshly distilled DCM (4 mL). To the resulting solution was then added under an argon counter-flow the cationic gold catalyst (2 mol\%). The solution was stirred until TLC monitoring showed complete conversion of the substrate (3 hours). The mixture was then filtered over a short pad of silica gel, the solvent was removed under reduced pressure and the crude was purified by flash column chromatography to yield the desired cycloisomerization derivative 6 as a colorless oil in $74 \%$ yield $(37 \mathrm{mg}) .{ }^{1} \mathrm{H}$ NMR (400 MHz, $\left.\mathrm{CDCl}_{3}\right) \delta 7.88-7.83(\mathrm{~m}, 2 \mathrm{H}), 7.62-7.54(\mathrm{~m}, 1 \mathrm{H}), 7.50-7.42$ (m, 2H), 7.41 (d, $J=1.6 \mathrm{~Hz}, 1 \mathrm{H}), 6.82(\mathrm{t}, J=2.4 \mathrm{~Hz}, 1 \mathrm{H}), 6.62(\mathrm{t}, J=2.8 \mathrm{~Hz}, 1 \mathrm{H}), 6.42(\mathrm{dd}, J=3.3,1.8 \mathrm{~Hz}$, $1 \mathrm{H}), 6.26(\mathrm{~d}, J=3.3 \mathrm{~Hz}, 1 \mathrm{H}), 3.12-3.02(\mathrm{~m}, 2 \mathrm{H}), 2.83-2.73(\mathrm{~m}, 2 \mathrm{H}) .{ }^{13} \mathrm{C}$ NMR $(101 \mathrm{MHz}$, $\left.\mathrm{CDCl}_{3}\right) \delta 194.2,154.3,148.8$ (2C), 144.2, 142.6, 141.7, 138.5, 133.0, 129.6 (2C), 128.5 (2C), 111.7, 110.6, 108.9, 32.1, 30.5. HRMS calcd. for $\mathrm{C}_{17} \mathrm{H}_{15} \mathrm{O}_{2}{ }^{+}(\mathrm{M}+\mathrm{H})^{+}$251.1067, found 251.1064.

\section{Acknowledgements}

We thank the CNRS, UPMC, IUF (L. F. and M.M.) and Ministère de l'Enseignement Supérieur et de la Recherche (A. S.) for financial support.

\section{References}

1. Ma, S. Ed., Handbook of Cyclization Reactions, Wiley-VCH: Weinheim, 2010.

2. Bertz, S. H. J. Am. Chem. Soc. 1981, 103, 3599-3601. http://dx.doi.org/10.1021/ja00402a071 
3. Anderson, E. A. Org. Biomol. Chem. 2011, 9, 3997-4006. http://dx.doi.org/10.1039/c1ob05212h

4. Inglesby, P. A.; Evans, P. A. Chem. Soc. Rev. 2010, 39, 2791-2805. http://dx.doi.org/10.1039/b913110h

5. Aubert, C.; Fensterbank, L.; Gandon, V.; Malacria, M. Top. Organomet. Chem. 2006, 19, 259-294.

6. Aubert, C.; Courillon, C.; Dhimane, A.-L.; Fensterbank, L.; Lacote, E.; Thorimbert, S.; Malacria, M. Curr. Opin. Drug Discov. Devel. 2002, 5, 928-936.

7. Jiao, L.; Yu, Z.-X. J. Org. Chem. 2013, 78, 6842-6848. http://dx.doi.org/10.1021/j0400609w

8. Zhang, D.-H.; Zhang, Z.; Shi, M. Chem. Commun. 2012, 48, 10271-10279. http://dx.doi.org/10.1039/c2cc34739c

9. Aubert, C.; Malacria, M.; Ollivier, C. in Science of Synthesis: Houben-Weyl/Stereoselective Synthesis; Evans, P. A. Ed.; Georg Thieme: Berlin, 2011; Vol. 3, pp. 145-242.

10. Aubert, C.; Fensterbank, L.; Garcia, P.; Malacria, M.; Simonneau, A. Chem. Rev. 2011, 111, 1954-1993. http://dx.doi.org/10.1021/cr100376w

11. Dominguez, G.; Perez-Castells, J. Chem. Soc. Rev. 2011, 40, 3430-3444.

12. Galan, B. R.; Rovis, T. Angew. Chem. Int. Ed. 2009, 48, 2830-2834. http://dx.doi.org/10.1002/anie.200804651

13. Michelet, V.; Toullec, P. Y.; Genêt, J.-P. Angew. Chem. Int. Ed. 2008, 47, 4268-4315. http://dx.doi.org/10.1002/anie.200701589

14. Butenschoen, H. Angew. Chemie, Int. Ed. 2008, 47, 5287-5290. http://dx.doi.org/10.1002/anie.200801738

15. Hashmi, A. S. K. Transition Metal-Catalyzed Cycloisomerizations of Allenes; Wiley-VCH: Verlag, 2004; Vol. 2, pp. 877-923.

16. Aubert, C.; Buisine, O.; Malacria, M. Chem. Rev. 2002, 102, 813-834. http://dx.doi.org/10.1021/cr980054f

17. Ojima, I.; Tzamarioudaki, M.; Li, Z.; Donovan, R. J. Chem. Rev. 1996, 96, 635-662. http://dx.doi.org/10.1021/cr950065y

18. Krause, N.; Winter, C. Chem. Rev. 2011, 111, 1994-2009. http://dx.doi.org/10.1021/cr1004088

19. Jimenez-Nunez, E.; Echavarren, A. M. Chem. Rev. 2008, 108, 3326-3350. http://dx.doi.org/10.1021/cr0684319

20. Shen, H. C. Tetrahedron 2008, 64, 7847-7870. http://dx.doi.org/10.1016/j.tet.2008.05.082

21. Leboeuf, D.; Simonneau, A.; Aubert, C.; Malacria, M.; Gandon, V.; Fensterbank, L. Angew. Chem. Int. Ed. 2011, 50, 6868-6871. http://dx.doi.org/10.1002/anie.201101179 
22. Tömösközi, I.; Bestmann, H. J. Tetrahedron Lett. 1964, 1293-1295. http://dx.doi.org/10.1016/S0040-4039(00)90468-4

23. Bestmann, H. J.; Hartung, H. Chem. Ber. 1966, 99, 1198-1207. http://dx.doi.org/10.1002/cber.19660990417

24. Bestmann, H. J.; Tömösközi, I. Tetrahedron 1968, 24, 3299-3319. http://dx.doi.org/10.1016/S0040-4020(01)92629-8

25. Bestmann, H. J.; Graf, G.; Hartung, H.; Kolewa, S.; Vilsmaier, E. Chem. Ber. 1970, 103, 2794-2801.

http://dx.doi.org/10.1002/cber.19701030912

26. Lang, R. W.; Hansen, H. J. Helv. Chim. Acta 1980, 63, 438-455. http://dx.doi.org/10.1002/hlca.19800630215

27. Oppolzer, W.; Chapuis, C.; Dupuis, D.; Guo, M. Helv. Chim. Acta 1985, 68, 2100-2114. http://dx.doi.org/10.1002/hlca.19850680803

28. Nieto-Oberhuber, C.; Munoz, M. P.; Bunuel, E.; Nevado, C.; Cardenas, D. J.; Echavarren, A. M. Angew. Chem. Int. Ed. 2004, 43, 2402-2406.

http://dx.doi.org/10.1002/anie.200353207

29. Mauleon, P.; Toste, F. D. in Modern Gold Catalyzed Synthesis; Hashmi, A. S. K. Ed.; WileyVCH: Weinheim, 2012; pp. 75-134. http://dx.doi.org/10.1002/9783527646869.ch4

30. Correa, A.; Marion, N.; Fensterbank, L.; Malacria, M.; Nolan, S. P.; Cavallo, L. Angew. Chem. Int. Ed. 2008, 47, 718-721. http://dx.doi.org/10.1002/anie.200703769

31. Marion, N.; Nolan, S. P. Angew. Chem. Int. Ed. 2007, 46, 2750-2752. http://dx.doi.org/10.1002/anie.200604773

32. Hashmi, A. S. K.; Schwarz, L.; Choi, J.-H.; Frost, T. M. Angew. Chem. Int. Ed. 2000, 39, 2285-2288. http://dx.doi.org/10.1002/1521-3773(20000703)39:13<2285::AID-ANIE2285>3.0.CO;2-F

33. Sromek, A. W.; Rubina, M.; Gevorgyan, V. J. Am. Chem. Soc. 2005, 127, 10500-10501. http://dx.doi.org/10.1021/ja053290y

34. Alcaide, B.; Almendros, P.; Alonso, J. M.; Fernandez, I. J. Org. Chem. 2013, 78, 6688-6701. http://dx.doi.org/10.1021/jo401013d

35. Fensterbank, L.; Malacria, M. Acc. Chem. Res. 2014, 47, 953-965. http://pubs.acs.org/doi/abs/10.1021/ar4002334 